\title{
A PERFORMANCE E O LOCAL DA CULTURA DE MANUSCRITOS CULINÁRIOS DE CONGREGAÇÕES RELIGIOSAS FEMININAS DE JOÃO PESSOA
}

\section{PERFORMANCE AND THE CULTURAL SITE OF CULINARY MANUSCRIPTS OF RELIGIOUS FEMALE CONGREGATIONS OF JOÃO PESSOA}

\begin{abstract}
Alessandra Gomes Coutinho Ferreira ${ }^{9}$
RESUMO: Os estudos sobre performance - a voz no corpo - e cultura permitem a compreensão de como estes dois campos de conhecimento revelam os modos de fazer de um determinado grupo. No campo da linguística aplicada, Moita Lopes (2007) pontua que as performances constroem identidades e as marcam. A investigação das marcas identitárias percebidas em performance permite compreender como a cultura foi fixada na estrutura e composição de manuscritos culinários de congregações religiosas femininas da cidade de João Pessoa durante o século XX. Dessa forma, é na linguagem e através dela que se conhecerão a performance e os locais da cultura presentes nesses registros de cozinha. Os manuscritos culinários revelam o que algumas freiras fixaram como memória das vozes, isto é, memória do que se comia nos diversos contextos comunicativos do cotidiano de mulheres. Sabe-se que a comida pontua as marcas culturais de um indivíduo, de um grupo e em um contexto mais amplo de uma sociedade. Assim, pretende-se analisar os manuscritos culinários dessas religiosas a fim de identificar, nas escrituras das receitas de cozinha, as vozes e as performances das freiras ao fixar a memória dos pratos e os locais da cultura dos manuscritos. Para isso, utilizou-se como fundamentação teórica os estudos de Zumthor (1993, 2007), Bhabha (2007), Ottoni (1998) e Moita Lopes (2007).
\end{abstract}

PALAVRAS-CHAVE: Manuscritos culinários. Escrituras. Performance. Local da cultura. Vozes.

ABSTRACT: Performance studies - the voice in the body - and culture allow for an understanding of how these two fields of knowledge reveal a group's ways of doing. In the field of applied linguistics, Moita Lopes (2007) points out that the performances construct identities and mark them. The investigation of perceived identity marks in performance allows us to understand how culture was fixed in the structure and composition of culinary manuscripts of female religious congregations of the city of João Pessoa during the 20th century. In this way, it is in language and through it that the performance and culture sites present in these kitchen records are known. The culinary manuscripts reveal what some nuns have fixed as memory of the voices, that is, memory of what one eats in the diverse communicative contexts of the daily life of women. It is known that food punctuates the cultural marks of an individual, a group and in a wider context of a society. Thus, it is intended to analyze the culinary manuscripts of these nuns in order to identify in the scriptures of cooking recipes, the voices and performances of the nuns by fixing the memory of the dishes and the places of the culture of the manuscripts. For this, the studies of Zumthor (1993, 2007), Bhabha (2007), Ottoni (1998) and Moita Lopes (2007) were used as theoretical basis.

KEYWORDS: Culinary Manuscripts. Scriptures. Performance. Place of culture. Voices.

O que tenho diante dos olhos, impresso ou manuscrito, é apenas um pedaço do tempo, coagulado no espaço da página ou do livro. ZUMTHOR, Paul. A letra e a voz.

\section{Introdução}

Cotejar manuscritos culinários de congregações religiosas femininas da cidade de João Pessoa, a fim de perceber a performance e o local da cultura no qual estão inseridos é desafiador. Investigar o que algumas freiras registravam em seus cadernos de cozinha,

\footnotetext{
${ }^{9}$ Mestre em Linguística pela UFPB. Especialista em Literatura e Ensino pelo IFRN. Graduada em Letras pela UFPB. Professora do Instituto Federal de Educação, Ciência e Tecnologia da Paraíba - IFPB campus Cabedelo. E-mail: alessandragcferreira@gmail.com
} 
exemplos de situações típicas do cotidiano dessas mulheres, é perceber a performance culinária de execução das receitas fixadas. A comida pontua as marcas culturais de um indivíduo, de um grupo e em um contexto mais amplo de uma sociedade. Esses manuscritos culinários são "pedaços do tempo", como dizia Zumthor (1993, p. 20), e descobri-los é tarefa imanente.

Os estudos sobre performance e cultura permitem a compreensão de como estes dois campos de conhecimento revelam os modos de fazer de um determinado grupo. A performance - a voz no corpo - é um conceito trabalhado por diversas áreas de saber como a literatura, através dos estudos de Paul Zumthor, a linguística aplicada, a antropologia, a psicanálise, entre outras áreas. A voz entranhada no corpo tem uma aura - unicidade da voz que remete à memória individual de quem a enuncia e consequentemente remete à memória coletiva, por este indivíduo fazer parte de um grupo e de uma comunidade.

O lugar ocupado pelo grupo identifica o plano cultural no qual está inserido e é neste plano que se investiga o modo como se formam indivíduos pertencentes a estes lugares, os valores trocados, as relações dialógicas priorizadas em cada grupo e os saberes colaborativos. No campo da linguística aplicada, Moita Lopes (2007) pontua que as performances constroem identidades e, por marcar a identidade, a performance é a cultura no corpo a partir de movimentos performáticos. Analisando o local da cultura, Homi Bhabha (2007, p. 20) destaca a importância da relação performance-cultura, afirmando que "os termos do embate cultural, seja através de antagonismo ou afiliação, são produzidos performativamente". É na linguagem e através dela que se conhecerão a performance e os locais da cultura supracitados. A partir desses estudos pretende-se analisar os manuscritos culinários de freiras residentes em João Pessoa durante o século $\mathrm{XX}$, a fim de identificar, nas escrituras das receitas de cozinha, as performances das freiras ao realizar os pratos e os locais da cultura dos manuscritos.

\section{A performance nos manuscritos culinários}

Os estudos sobre performances são fundamentais para a "compreensão dos modos como e por meio dos quais nos representamos e repetimos encenações na vida cotidiana, uma vez que a atuação na vida cultural só se concretiza em performances" (MOITA LOPES, 2007, p. 11). As ações cotidianas de executar receitas culinárias apontam maneiras de compreender o pensar e o sentir das freiras das congregações religiosas femininas da cidade a partir de suas performances culinárias, como também das performances dos leitores/ouvintes das narrativas de cozinha. Nos dizeres de Paul Zumthor (1993, p. 219):

\footnotetext{
Para ouvir a voz que pronunciou nossos textos, basta que nos situemos no lugar em que seu eco possa talvez ainda vibrar: captar uma performance, no instante e na perspectiva em que ela importa, mais como ação do que pelo que ela possibilita comunicar. Trata-se de tentar perceber o texto concretamente realizado por ela, numa produção sonora: expressão e fala juntas, no bojo de uma situação transitória e única. A informação transmite-se assim num campo dêitico particular, jamais exatamente reproduzível, e segundo condições variáveis, dependendo do número e da qualidade dos elementos não lingüísticos em jogo.
}

As vozes que enunciaram as receitas fixadas em manuscritos culinários de congregações religiosas femininas da cidade de João Pessoa são captadas pela performance, isto é, a voz no corpo em ação. A performance é a concretude do texto numa "situação transitória e única", como se as receitas fossem executadas no momento da enunciação através de elementos que transcendem os "elementos linguísticos em jogo", isto é, há "elementos marginais, que se relacionam à linguagem e raramente codificados (o gesto, a 
entonação), ou situacionais, que se referem à enunciação (tempo, lugar, cenário)" (ZUMTHOR, 2007, p. 75).

Os "elementos marginais", "o gesto e a entonação", que são dificilmente codificados, podem ser percebidos nos manuscritos culinários analisados. Os registros culinários enunciam um fazer, uma performance. As performances foram fixadas em escrituras de cozinha através da "voz que emana do corpo" (ZUMTHOR, 1993, p. 15), observadas pelo modo de fazer e criar as delícias culinárias. Austin (apud LOPES et ali, 2007, p. 9) afirma que "a linguagem, em vez de meramente descrever o mundo, o afeta e constrói". E é nessa construção do mundo que são observadas as artes de fazer receitas culinárias de religiosas das congregações femininas de João Pessoa. Um exemplo de performance culinária pode ser observado com a descrição da receita Panqueca dos escoteiros ${ }^{10}$, fixada em um manuscrito culinário de meados dos anos 50 do século $\mathrm{XX}$ da congregação religiosa feminina de Jesus Crucificado, localizada no bairro de Castelo Branco III em João Pessoa, através de uma voz que ordena e enuncia o modo como a receita deve ser executada:

\begin{abstract}
Bata no liquidificador quatro ovos, três colheres de sopa de maisena, três colheres de sopa de farinha de trigo, uma colher de sopa de óleo, três xícaras de leite, uma pitada de sal. Pincele a frigideira que deve ser do tamanho das panquecas. Frite todas e vá empilhando numa travessa à parte. Recheie a gosto acomodando-as num recipiente refratário. Cubra com molho de tomates e queijo ralado. Leve ao forno para gratinar. Sirva quente.
\end{abstract}

Lê-se e vê-se a receita sendo executada: "bata no liquidificador", "pincele a frigideira", " frite", "empilhe numa travessa", "recheie a gosto", "cubra com molho", "leve ao forno", "sirva quente". Percebem-se as imagens dos gestos em ação pela voz de mando. Esta voz comanda a partir dos verbos imperativos ao mesmo tempo que faz e executa o que está sendo dito. Esta performance, nos dizeres de Goffman (apud LOPES et ali, 2007, p. 10) sobre a sociologia interacional, indica que "a realidade se constrói por meio de papéis encenados por atores sociais, para além da consciência que têm disso". As receitas culinárias demonstram a ação desses atores sociais, uma voz que comanda e um outro que ouve/lê e participa ativamente da mesma ação.

A descrição do modo de fazer a Panqueca dos escoteiros permite a visualização dessa voz em ação, uma voz que ordena e que indica como se deve fazer, ao mesmo tempo em que os ingredientes - ovos, maisena, farinha de trigo, óleo, leite, sal - utilizados na realização do prato, sinalizam o que se comia na época em que a receita foi fixada. Esses ingredientes são recorrentes na realização de diversos tipos de receitas como: panquecas, bolos, biscoitos, doces, massas, mas unidos para fazer a receita da Panqueca dos escoteiros constituem a aura dessa receita, que tem lugar na memória da irmã que a fixou, na congregação religiosa na qual faz parte, no bairro do Castelo Branco III e na cidade de João Pessoa.

Outras combinações desses ingredientes, ora acrescentando ora eliminando, das receitas formam diversos pratos provenientes de uma mesma base. O léxico das receitas observadas por títulos como - Panqueca dos escoteiros, Ambrosia, Bolo econômico, Knofes alemão, Licor de abacaxi, Peta, Cuca, Bolo do Piauí, Pão italiano, Bombinha da vovó, Arroz campeão, Bolo Sousa Leão, Pão Biscuit, Fofinhos de minuto, Pão de água, entre outros apontam o tempo e o lugar da freira como sujeito social, do grupo, do bairro e da cidade, bem

\footnotetext{
${ }^{10}$ Preservou-se o registro escrito das mulheres que escreveram as receitas culinárias. Os erros ortográficos nos registros das receitas, que serão percebidos no corpo do texto, foram uma escolha da pesquisadora que resolveu preservar a escrita feminina nos cadernos de receita analisados.
} 
como seus interesses, prioridades, valores e saberes. Portanto, são sinalizadores da cultura na qual a congregação religiosa está inserida.

Em relação aos "elementos situacionais" (tempo, lugar e cenário) dos manuscritos culinários congregacionais, investiga-se a descrição do espaço dos manuscritos como lugar fundamental para a compreensão da performance. O cenário a ser descrito é o da cozinha, o lugar refere-se ao espaço em que estão localizadas as congregações religiosas femininas da cidade de João Pessoa, e o tempo é o século XX. O cenário descrito pelos manuscritos culinários é um espaço mágico repleto de colheres de sopa, colheres de pau, xícaras, fogões, pratos, copos, liquidificadores, frigideiras, pirex, fornos, refrigeradores, vidros, colheres de café, colheres de chá, peneiras, assadeiras, pires, panelas, panos, mármores, papéis celofane, facas, espremedores, tigelas, fôrmas, garrafas, tabuleiros, vasilhas, forminhas que deram forma às diversas receitas fixadas nos cadernos de receitas. Através desses utensílios de cozinha foram manuseados os ingredientes utilizados na época da fixação das receitas como banha, farinha de trigo, leite, manteiga, espinafre, queijo parmesão, batata inglesa, batata doce, cebolas, tomates, azeite de oliva, arroz, ovos, sal, açúcar, pó royal, óleo, mostarda, suco de limão, água, laranja, maisena, rapadura, amendoim, farinha de mandioca, salsichas, lagarto (carne verde), vinagre, pimenta, cheiro verde, cenouras, azeite doce, salsa, cebolinha, azeitona, milho verde, creme de leite, goma, macacheira, coco, abacaxi, gelatina, tapioca, macarrão. Os ingredientes e os utensílios de cozinha, alicerces das receitas culinárias, delineiam as formas das receitas constituídas em performance. Cada utensílio e cada ingrediente utilizados sugerem novas formas de performances e modos de interação com o leitor/ouvinte de receitas, pois fazem sentido pela memória coletiva da culinária local, logo são formadores de relações de sentido.

Zumthor (1993, p. 219), preocupado em compreender e descrever as regras que regem "todo ato de comunicação" e suas relações de sentido, enumera três regras para a descrição do fenômeno: as primeiras são as "regras próprias a toda emergência da linguagem em discurso"; as segundas são as "regras típicas de tal procedimento discursivo" e as terceiras são as "regras particulares para cada situação vivida". Essas regras que regem todo e qualquer ato de comunicação podem ser percebidas nos manuscritos culinários. As primeiras regras se referem ao modo como os manuscritos de cozinha são organizados e estruturados, isto é, pertencem a uma lógica própria de leis internas organizacionais que constituem a formação de manuscritos culinários a partir da fixação de receitas de cozinha, seja da ordem religiososagrada, de freiras, seja da ordem profana, de donas de casa. Todos os manuscritos culinários - sagrados ou profanos - obedecem às mesmas leis de constituição. As segundas regras elencadas referem-se às características do procedimento discursivo de um texto, isto é, o que torna uma receita culinária um texto com características próprias como descrição de ingredientes e modos de fazer associados às vozes de mando que imperam nas receitas culinárias. E as terceiras regras sinalizadas são as características peculiares a cada situação vivida, isto é, o que marca cada manuscrito culinário como pertencente a uma determinada congregação religiosa.

São as movências discursivas, a amplitude das variações das receitas, que muitas vezes tornam a performance difícil de ser observada, pois esta traz a marca de quem registrou a receita culinária - memória individual - associada à memória coletiva do grupo congregacional. Mas Zumthor (1993, p. 221) pontua como analisar essas vozes em performance:

Por cruzamento de feixes de informações, por deslocamentos de perspectiva e de visada, a partir de um ponto de vista intuitivamente escolhido, esforçamo-nos para sugerir um acontecimento: o acontecimento-texto; representar o texto-emato, integrar essa representação no prazer que se sente na leitura. Nossos textos só nos oferecem uma forma vazia, e sem dúvida profundamente alterada, do que, em outro contexto sensório-motor, foi palavra-viva. 
Esses cruzamentos de informações foram feitos a partir dos inventários das receitas culinárias do manuscrito das Irmãs Missionárias de Jesus Crucificado e dos quatro manuscritos das Irmãs Franciscanas de Dillingen. As primeiras desenvolvem trabalhos de evangelização com comunidades carentes, e as segundas, além de desenvolver esse mesmo tipo de trabalho, dedicam-se à educação cristã através do Instituto João XXIII dedicado a todos os níveis de ensino da educação básica. Os manuscritos das Irmãs Franciscanas de Dillingen são salvo-guardados por uma irmã que mora no Bairro dos Estados, localizado na cidade de João Pessoa.

Observa-se como a receita de Pão-de-ló no manuscrito culinário das Irmãs de Jesus Crucificado foi fixada. É uma receita presente em praticamente todos os manuscritos culinários do século XX, faz parte da memória da cidade e da cultura local. Nesse manuscrito, há dois registros dessa receita, cada uma fixada com letras diferentes. A primeira receita apresenta uma letra no formato itálico, enquanto a segunda receita apresenta uma letra com um formato arredondado. Não foi a mesma pessoa que fixou. Observe a descrição da receita na tabela 1.

\begin{tabular}{|l|l|}
\hline \multicolumn{1}{|c|}{ Pão de ló p. 3 } & \multicolumn{1}{|c|}{ Pão de ló p. 33 } \\
\hline 4 ovos, 4 colheres de sopa de açucar, 4 & 7 ovos, 7 colheres de farinha de trigo, \\
colheres de sopa de farinha de trigo, 1 colher & leite, o quanto baste, 1 colher (sopa) de \\
de chá de fermento em pó. & fermento. \\
Modo de fazer: Bata as claras em neve, junte & Modo de fazer: Bata as gemas com o \\
as gemas e bata bem. Passe juntos pela & açucar, até esbranquiçar. Junte a farinha \\
peneira: o açucar, a farinha de trigo e o & de trigo peneirada e o leite necessário a \\
fermento. Vá adicionando esta mistura aos & dar consistência de bolo. Acrescente as \\
ovos. Coloque em assadeira untada com & claras batidas em neve e fermento, \\
manteiga e polvilhada com farinha de trigo. & misturando devagar. Numa assadeira \\
& untada asse em forno brando. \\
\hline
\end{tabular}

Quadro 1 - Receitas de pão de ló da Congregação religiosa feminina de Jesus Crucificado

Eis o primeiro cruzamento de receitas em um mesmo manuscrito culinário conforme Quadro 1. No Quadro 2, há mais um exemplo de cruzamento de receitas de Bolo de macacheira fixadas em manuscritos culinários de congregações religiosas femininas diferentes: a primeira receita desse bolo pertence ao único manuscrito da Congregação de Jesus Crucificado localizado no bairro de Castelo Branco III, e a segunda receita do bolo de macacheira pertence ao manuscrito $\mathrm{n}^{\mathrm{o}} 1$ da Congregação das Franciscanas de Dillingen.

\begin{tabular}{|l|l|}
\hline \multicolumn{1}{|c|}{ Bolo de macacheira p. 11 } & \multicolumn{1}{c|}{ Bolo de macacheira p. 105 e 106 } \\
\hline \multicolumn{1}{|c|}{ Irmãs de Jesus Crucificado } & \multicolumn{1}{c|}{ Irmãs Franciscanas de Dillingen } \\
\hline $\begin{array}{l}\text { 6 ovos batidos como para pão de ló, 4 xícaras } \\
\text { de macacheira, 3 xícaras rasas de açúcar, 1 } \\
\text { xícara de coco ralado, 1/2 copo de leite de } \\
\text { coco, } 3 \text { colheres de trigo, } 3 \text { colheres de } \\
\text { fermento, } 5 \text { colheres de queijo ralado, } 1 \\
\text { pitada de sal. Peneire a farinha com o } \\
\text { fermento e o açúcar. Junte os ovos e demais } \\
\begin{array}{l}\text { ingredientes. Misture tudo e asse em forma } \\
\text { untada. }\end{array}\end{array}$ & $\begin{array}{l}\text { manteiga, 250 gramas de açucar, leite de 1 } \\
\text { côco tirado sem água e 6 ovos. Rala-se a } \\
\text { macacheira, espreme em um pano, passa } \\
\text { na peneira a massa com o açucar, uma } \\
\text { colherinha de sal, depois bate-se a } \\
\text { manteiga com o leite de côco, bate-se os } \\
\text { ovos, mistura-se tudo, ponha no fôrno, } \\
\text { ponha uma colher de fermento em pó. }\end{array}$ \\
\hline
\end{tabular}


Analisando os dois quadros, percebe-se a primeira distinção referente à estrutura das receitas culinárias. $\mathrm{Na}$ descrição do "Pão de ló", vê-se a separação entre os ingredientes e o modo de fazer, o que não ocorre com a receita do "Bolo de macacheira" descrito no mesmo manuscrito das Irmãs de Jesus Crucificado. As estruturas das receitas culinárias variam de receita em receita. Os manuscritos culinários das Irmãs Franciscanas de Dillingen apresentam suas receitas ora com a separação dos ingredientes e modos de fazer, ora a descrição em conjunto das receitas, prevalecendo a descrição em conjunto dos ingredientes e modos de fazer numa narrativa única. Varia-se também a quantidade de ingredientes utilizados na fabricação das receitas, marcando a identidade de cada prato. Os ingredientes são os mesmos, mas a performance é distinta, denotando a sua unicidade, a sua singularidade. Muda-se a ordem de execução, muda-se a performance e consequentemente os gostos, aromas e sabores dos pratos. As receitas são de pão de ló, porém com cheiros e sabores diferentes. O mesmo ocorre com a receita do "Bolo de macacheira" do Quadro 2. A base dos ingredientes é a mesma, porém a voz em ação - a performance - é diferente acarretando em sabores diversos. A "narrativa" das receitas culinárias denotam uma situação particular, definível em termos individuais, em termos sócio-históricos, e na ordem das percepções do corpo. Essas performances das receitas dos quadros 1 e 2, analisadas através dos estudos zumthorianos, corroboram os estudos de performance de Moita Lopes (2007, p. 31) quando afirma: "a performance nunca é uma mera representação do texto, uma repetição em cena dos significados do que foi escrito. A própria materialidade da cena e o contexto em que ela ocorre contribuem para gerar significados novos e imprevisíveis". Logo, são esses significados novos e imprevisíveis que denotam as variantes de uma mesma receita culinária.

\section{O local da cultura das receitas culinárias}

Após a discussão sobre a performance das receitas culinárias dos manuscritos das freiras, tem-se o momento exato de observar o movimento cultural dessas performances. Estas performances são constituídas por identidades diversas. Em um mesmo manuscrito foram verificadas letras diversas que pontuam as identidades fragmentadas de um sujeito individual, bem como de um sujeito social devido à transitoriedade do tempo e as emergências de receitas culinárias de um tempo histórico fragmentado - Biscoito Delícia, Biscoitos saborosos, Biscoitos Lili, Sinha de araruta, Biscoitos de Sera, Bolachas de canela, Sequilhos de côco, Biscoito de nata, Biscoitos de milho, Biscoitos da titia, Raiva de goma, Cequilho de goma, Biscoito de nata, Amor perfeito, Bolachinhas de Fuba, Rosquinhas de Araruta.

Biscoitos e bolachas que refletem e refratam um tempo histórico e um local da cultura. Através das tradições culinárias, a memória da congregação religiosa persiste e se expressa na e pela linguagem. Tentar definir cultura não é uma tarefa das mais fáceis, tendo em vista a complexidade do termo, compreende-se a cultura como um "realinhamento das fronteiras culturais" pelos estudos de Homi Bhabha. Para este teórico, "o local da cultura" é a arte do presente percebida pelo sujeito considerado o produtor da linguagem. As receitas culinárias são singulares, possuem uma história a ser contada através da voz e da performance, que é também a reatualização da receita no presente, permitindo a troca simbólica entre os locais da cultura do presente com os locais da cultura do passado.

Os locais da cultura dos manuscritos culinários são os "entre-lugares" da performance culinária como espaços de identidades, pois justificam a permanência de receitas como Brevidade, Beijo de freira, Cocada de Pucha, Docinho Moderno, Olho de sogra, Amendoim caramelado, Balas de café, Brigadeiro, Broas delicadas, Bolo São Benedito, Bolo Luís Felipe, Bolo Imperador, Bolo Santo Antônio Casamenteiro, Bolo 7 de Setembro, Bolo Fino, Bolo Senhor, Bolo de Carimã, Bolo de pobre, Bolo Nega maluca, Bolo Souza Leão, Bolo Rei Alberto, entre outros - sinalizadoras de espaço-tempos que fazem sentido para a congregação 
religiosa das Irmãs de Jesus Crucificado que fixaram as receitas da memória da cidade pessoense. Certamente, para outras cidades brasileiras, algumas receitas farão sentido e outras não, porque remetem para as peculiaridades de cada cidade. Percebem-se, a partir do léxico das receitas supracitadas, muitas que denotam fatos históricos e personalidades históricas Bolo Luís Felipe, Bolo Imperador, Bolo 7 de Setembro, Bolo Rei Alberto; outras que revelam a transitoriedade da vida - Brevidades, docinho moderno; outras que apresentam motivos religiosos - Bolo São Benedito, Bolo Santo Antônio Casamenteiro, Bolo Senhor; receitas do cotidiano e de festas - olho de sogra, cocada de Pucha, amendoim caramelado, balas de café, brigadeiro, broas delicadas, bolo fino, bolo de carimã, bolo de pobre, bolo nega maluca, bolo souza leão.

As identidades pontuadas pelos títulos das receitas culinárias são variadas. Percebemse identidades da vida privada e da vida pública dessas irmãs e como elas pensavam e se expressavam através da seleção de receitas fixadas nos manuscritos. São irmãs amantes da religião, preocupadas com os rumos históricos do país, com os espaços e tempos vividos. Essa moldura do tempo histórico revela a construção do que as pessoas são através da performance.

\begin{abstract}
Privado e público, passado e presente, o psíquico e o social desenvolvem uma intimidade intersticial. É uma intimidade que questiona as divisões binárias através das quais essas esferas da experiência social são frequentemente opostas espacialmente. Essas esferas da vida são ligadas através de uma temporalidade intervalar que toma a medida de habitar em casa, ao mesmo tempo em que produz uma imagem do mundo da história. (BHABHA, 2007, p. 35)
\end{abstract}

A cultura revelada pela performance sinaliza tudo o que é apreendido, tudo o que é absorvido socialmente. Segundo Bhabha (2007, p. 21),

o reconhecimento que a tradição outorga é uma forma parcial de identificação. Ao reencenar o passado, este introduz outras temporalidades culturais incomensuráveis na invenção da tradição. Esse processo afasta qualquer acesso imediato a uma identidade original ou a uma tradição "recebida".

A importância da tradição, segundo este autor, só pode ser compreendida parcialmente. As performances como reatualizações de ações vividas demonstram novas temporalidades e novos significados, logo é quase impossível pensar em uma identidade única. Há várias identidades percebidas de acordo com o contexto na qual está inserida, por isso há vários fragmentos identitários nos manuscritos culinários. A noção de ambivalência, característica dos estudos de Homi Bhabha (2007), refere-se ao fato de algo ser sempre retomado, mas de forma diferente. É o que ocorre com as escrituras das receitas. Muitas delas são reiteradas ao longo de décadas, mas sempre de maneira diferente. "O trabalho fronteiriço da cultura [...] renova o passado, refigurando-o como um 'entre-lugar' contingente, que inova e interrompe a atuação do presente" (BHABHA, 2007, p. 27).

A análise de como opera o texto dos manuscritos culinários a partir dos estudos da performance revela a constituição do "lócus emocional em que o texto vocalizado se torna arte", conforme pontua Zumthor (1993, p. 222).

A voz em performance é uma voz em diálogo. As vozes de mando das receitas culinárias sinalizam o dialogismo. "Na maioria das vezes, a intervenção dialógica articula-se sobre um verbo que denota a audição, audire, ouîr, escouter, hören, de preferência no imperativo, às vezes no condicional" (ZUMTHOR, 1993, p. 225). A interação entre quem executa a receita e quem a percebe é recíproca, há um diálogo de corpos em ação, em performance, que se alimentam mutuamente e que têm lugar no instante único dos gestos do corpo. O que Zumthor (1993) e Moita Lopes (2007) teorizam como performance, Bhabha 
chamou de mímica, isto é, "aquela forma de diferença que é quase o mesmo, mas não exatamente" (2007, p. 134).

\section{Considerações finais}

A cozinha como linguagem não é um tema novo nos estudos acadêmicos. Esta temática já havia sido introduzida por Lévi-Strauss e corroborada por Câmara Cascudo ao ressaltar que a alimentação transcende o ato biológico e revela os planos sociológicos e culturais. Para Maciel (2004, p. 2), a cozinha pode ser compreendida como "um vetor de comunicação, um código complexo que permite compreender os mecanismos da sociedade à qual pertence, da qual emerge e a qual lhe dá sentido". A performance, em conjunto com o local da cultura dos manuscritos cotejados, revela esses vetores de comunicação de freiras que pensavam e sentiam o mundo e a vida colecionando receitas de cozinha. As receitas descrevem uma grande viagem cultural pelos rastros da sociedade pessoense do século XX.

As receitas de cozinha fixadas nos manuscritos culinários das freiras residentes em João Pessoa tornam-se marcas identitárias através das quais se pode distingui-las. São estilos de vida e modos pertencentes não só a quem fixou as receitas como também à memória coletiva do grupo congregacional analisado. Se "o ouvinte-espectador espera, exige que o que ele vê lhe ensine algo mais do que simplesmente o que ele vê, revele-lhe uma parte escondida desse homem, das palavras, do mundo" (ZUMTHOR, 1993, p. 229).

A voz no corpo - performance - "não é mais a mera voz que pronuncia: ela configura o inacessível; e cada uma de suas inflexões, de suas variações de tonalidade, de timbre, de altura combina-se e encadeia-se como uma prosopopéia do vivido" (ZUMTHOR, 1993, p. 229). As escrituras das receitas são lembranças do vivido percebidas em performance. Sua graça e leveza permitem o não esquecimento e constitui, assim, o capital simbólico da sociedade de João Pessoa do século XX, demarcador do local da cultura dos manuscritos culinários das freiras.

\section{Referências}

\section{Fontes Primárias}

Manuscrito Culinário da Congregação Religiosa Feminina de Jesus Crucificado. João Pessoa, s/d.

Manuscrito Culinário $\mathrm{n}^{\mathrm{o}} 1$ da Congregação Religiosa Feminina Franciscanas de Dillingen. João Pessoa, s/d.

\section{REFERÊNCIAS}

BHABHA, H. O local da cultura. Tradução de Myriam Ávila, Eliana Lourenço de Lima Reis, Gláucia Renate Gonçalves. Belo Horizonte: Ed. UFMG, 2007.

CAMARA CASCUDO, L. História da Alimentação no Brasil: pesquisa e notas. Belo Horizonte, Itatiaia, 1983.

LÉVI-STRAUSS, C. Mitológicas I - O cru e o cozido. Tr. Beatriz Perrone Moisés, R.J.: Cosac e Naify, 2004.

. Mitológicas 11 - Do mel às cinzas. Tr. Carlos Eugênio Marcondes de Moura, R.J.:

Cosac e Naify, 2005.

MACIEL, M. E. Uma cozinha à brasileira. In: Revista Estudos Históricos. Rio de Janeiro, $\mathrm{n}^{\circ}$ 33, 2004. 
OTTONI, P. R. Visão performativa da linguagem. Campinas, SP: Editora da Unicamp, 1998.

MOITA LOPES, L. P.; DURÃO, F. A.; ROCHA, R. F. da (Org.). Performances: estudos de literatura em homenagem a Marlene Soares dos Santos. Rio de Janeiro: Contra Capa Livraria, 2007.

ZUMTHOR, P. A letra e a voz. Trad. Amálio Pinheiro, Jerusa Pires Ferreira. São Paulo: Companhia das Letras, 1993.

. Performance, recepção, leitura. Tradução Jerusa Pires Ferreira; Suely Fenerich.

São Paulo: Cosac Naify, 2007. 